tions, Office for Technical and Scientific Research for France Oversea, Bondy, France ; and the physical aspects by Prof. W. R. van Wijk, Agricultural University of Wageningen, Netherlands. Dr. Ayers served as general technical director.

Reclamation of saline soils and use of saline water for irrigation are problems of primary importance in Tunisia. This was stressed by the President of the Republic of Tunisia, Habib Bourguiba, who opened the conference and welcomed the group. Prof. Kovda, director of the Unesco Department of Natural Sciences and one of the foremost Russian soil scientists, thanked the president on behalf of Unesco. Prof. Kovda stayed at Tunis during the first week of the course. He and several French scientists, consultants to the Tunisian Government, gave lectures on special subjects as capillary rise of saline ground water, genesis of saline soils, Tunisian soils, plant associations in Tunisia, crop research in Tunisia, distribution and quality of surface and underground waters in Tunisia. The Secretary of State for Education, Mahmoud Messadi, the Secretary of State for Agriculture, Abdessalam Kenani, and many other Tunisian authorities attended at one or more lectures.

The lectures and laboratory work were held in the Ecole Supérieure d'Agriculture (director Prof. Haffani), where also the participants were housed. There were thirty-two participants from ten Middle East countries. Of these, fifteen were from Tunisia, the others from Iran, Iraq, Jordan, Lebanon, Lybia, Morocco, Sudan, Turkey and the United Arab Republic. Most of the participants were graduate staff members of universities or research institutes and several held responsible positions in their countries.
The enthusiasm and interest of the participants contributed much to the success of the course.

The field trip was offered by the Tunisian Ministry of Education. Leaders were Prof. G. Aubert and Mr. Roederer, head of the Pedological Service of the Ministry of Education. First the Medjerda valley was visited where an ambitious and magnificent project of reclamation, land amelioration and irrigation is in progress. Thereafter the arid and desert areas in the south were visited where a variety of soils of different degrees of salinity were studied. The capriciousness of the weather and the statistical meaning of the concept of climate were convincingly demonstrated on that occasion. A heavy thunderstorm caused a delay of several hours before the 'Landrovers' could cross the flooded parts of the route Kairouan-Gafsa (annual precipitation between 4 in. and 8 in.) and the main road Gafsa-Tozeur was badly damaged. From Tozeur the field trip went to Kebili and Gabes, crossing the famous salt marsh of Chott el Djerid. The plans were to visit the fast saline area around Gabes. Again, however, a heavy thunderstorm interfered. The expedition was practically isolated for two days in Gabes as the environments were flooded, and then had to return to Tunis.

This note on the Salinity Course would be incom. plete if no mention were made of the hospitality which the participants and in particular the Unesco instructors received from officials and private persons, Tunisian as well as French. On such visits the impressive achievements but also the still remaining problems of the young Republic in the fields of education, public health, organization and employment of labour were frankly discussed.

\title{
THE NATIONAL CHEMICAL LABORATORY
}

$\mathrm{T}$ HE Report of the National Chemical Laboratory for 1958 follows the same general lines as previous reports (Department of Scientific and Industrial Research. Report of the National Chemical Laboratory, 1958. Pp. iv +97. London: H.M. Stationery Office, 1959. 5s. 6d. net). After a preliminary statement that the name of the Laboratory has been changed to indicate more precisely its true functions and that a steering committee is now responsible for the research programme, the Report sets out the various lines of work on which the Laboratory has been engaged. Broadly speaking, these fall into six main groups : the extraction of metals, the preparation of pure elements and compounds and the determination of their properties, the corrosion of metals, the development of new materials, analytical research and services, and microbiology. Some at least of these divisions have been represented by work in the Laboratory over a period of years, that on the corrosion of metals being a special case in point. Each year, however, new problems have come forward and as a result it appears that the staff of the Laboratory is now much larger than it was formerly.

In addition to its own work the Laboratory has for some years maintained an advisory service. Each year numerous inquiries are received for advice and assistance on all topics related to its own work, particularly such as concern the corrosion of metals and the purification of organic compounds. In addition, the Laboratory is often approached for advice on topics quite outside the scope of its researches. One example mentioned in the field of corrosion is that of the pitting of domestic copper piping in a housing scheme, and others show that this advisory service must be a valuable feature of the general activity of the Laboratory and that the problems coming in through it may sometimes prove very suggestive and important in relation to its own work.

The parts of the Report dealing with corrosion show that some fundamental work on the mechanism of corrosion is proceeding alongside investigations on various aspects of more directly practical interest, such as those on inhibitors. Work on the extraction of metals included studies of the extraction and recovery of uranium from a variety of ores, which is of interest to the United Kingdom Atomic Energy Authority, and on the separation of the rare earths. Of special interest is the section of the Report dealing with the preparation and properties of pure elements and compounds. In the case of metals it has long been known that the presence of even minute traces of impurities, sometimes so small as to prove extremely difficult to detect by ordinary analytical procedures, can lead to profound changes in properties such as hardness and chemical activity. The increasing importance of pure metals in modern metallurgical technology makes this part of the work of the 
Laboratory of great interest. The zone-refining technique has necessarily played an important part.

The section of the Report dealing with the development of new materials is largely concerned with ion-exchange resins and the permeability of membranes. This part is written up in rather greater detail than the rest of the Report and hence makes interesting reading. The underlying ideas are more carefully presented, and there are good graphs of the results. As a general criticism it might be said that a good deal of the rest of the Report is presented so briefly that it cannot arouse much interest except among specialists, but the part on now materials does seem to have achieved something in this direction. It would be unfair to contrast with this the eleven. page catalogue of strains of bacteria at the end, but the different parts of the Report vary quite considerably in appeal to the non-specialist scientific reader, and perhaps in future greater attention could be given to this aspect. It has obviously been a difficult problem for the director and his staff to compress their material into pre-ordained limits, but a tendency to produce information as from one specialist to another has cramped the style in some cases.

The general work in the Laboratory now includes emission and infra-red spectroscopy, micro-analysis and polarography. The first two might seem to encroach to some extent on the field of the National
Physical Laboratory, but the researches are evidently directed towards chemical problems. Some work on various compounds of boron is of interest although it seems to have been limited to organic compounds. The immediate aim, it is said, has been to provide background knowledge of the chemistry of the boron nitrogen system and to prepare a range of intermediates from which thermally stable and other useful materials may be made. The general impression conveyed by the Report is that inorganic chemistry, which has now become of extreme importance, has perhaps received less attention than it should do, and the metals have, perhaps understandingly, monopolized a large share of the interest in the field.

The Report as a whole is a record of work of great value, but with the extension of staff and work the question must arise whether it is now possible to cover the results in an interesting and understandable way in less than a hundred pages. It is true that much of the work will ultimately be published in a more extended form, but it will then tend to be lost in the enormous field of specialist literature. It might be worth considering whether the Report could be enlarged to double its present size (and, of course, at greater cost to the purchaser) and an attempt made at the same time to deal with topics of wider interest in a way which would attract the general scientific reader. J. R. PARTINGTON

\section{MUTATION OF BACTERIA AT HIGH LEVELS OF SURVIVAL BY ETHYL METHANE SULPHONATE}

\section{BY ANTHONY LOVELESS}

Chester Beatty Research Institute, London, S.W.3
AND

\author{
SHEILA HOWARTH \\ Guinness-Lister Research Unit, Lister Institute of \\ Preventive Medicine, London, S.W.I
}

$\mathrm{E}$ THYLATION was first described as a mutation. inducing process ("alkylation of the gene molecule") by Rapoport", who used diethyl sulphate as the reagent and Drosophila melanogaster as the test material. Subsequent work has revealed that ethylating agents appear to have unique properties as mutagens in a number of systems. Thus, treatment of phage $T 2$ in vitro by either diethyl sulphate or ethyl methane sulphonate results in a considerably increased yield of both plaque-type and host-range mutants in the first cycle of infection by the treated phage of untreated cells of Escherichia coli strain $B$ (ref. 2) and strain $B / r$ (Loveless, unpublished). No other alkylating agents have so far been reported as sharing this property. Heslot et al. ${ }^{3}$ have reported that the yield of mutants afforded by barley seeds treated with ethyl methane sulphonate much exceeds that of seeds treated with a wide variety of other alkylating agents; diethyl sulphate, also, was found to have unusual properties ${ }^{4}$. Kølmark ${ }^{5}$ found that diethyl sulphate provoked an appreciable number of reversions at an inositol locus of Neurospora which had proved relatively intractable to other reagents. There is no evidence from the results of the Fahmys ${ }^{6}$ of any dramatic mutagenic effect of ethyl methane sulphonate in Drosophila in comparison with its homologues, but it is probable that this compound was not tested at the high doses which its low toxicity, as measured in other organisms, might be expected to permit. D. M. Green (personal communication) has reported confirmation of the results with $T 2$ phage and an extension of the finding to $T 4$.

There was thus reason for supposing that the unusual genetic effects of ethylation were widespread in the organic world, and we were accordingly prompted to investigate the mutagenic effect of ethyl methane sulphonate upon bacteria. We wish now to report the production, consequent upon treatment with this compound, of high yields of revertants of a cystine-requiring mutant of Salmonella typhimurium strain LT2 and of mutations to phage T6resistance in Escherichia coli strain $B$ and $B / r$. In addition, preliminary experiments yielded five auxotrophic mutants of $S$. typhimurium strain LT2 out of 1,090 colonies tested, each having a different nutritional requirement.

(1) S. typhimurium strain $L T 2$, cys $A-21^{3}$ (requiring cystine) was grown in synthetic $(M-9)$ medium plus cystine at $40 \mu \mathrm{gm}$. $/ \mathrm{ml}$. from a $1: 100$ inoculum from an overnight culture in the same medium. At approximately $2 \times 10^{8}$ cells $/ \mathrm{ml}$. the culture was spun, washed in $M-9$ medium lacking cystine and resuspended at $c .10^{10} / \mathrm{ml}$. in a small volume $(c$. $3 \mathrm{ml}$.) of $0.4 M$ ethyl methane sulphonate for $15 \mathrm{~min}$. treatment at $37^{\circ} \mathrm{C}$. (Survival tests carried out inde. pendently showed that this treatment left about 70 per cent viable cells; in the mutation experiments the actual recovery was only $10-20$ per cent owing, 